\title{
Snow pack in the Swiss Alps under changing climatic conditions: an empirical approach for climate impacts studies
}

\author{
Martin Beniston, Franziska Keller, and Stéphane Goyette \\ Department of Geosciences, University of Fribourg, Switzerland
}

\begin{abstract}
In many instances, snow cover and duration are a major controlling factor on a range of environmental systems in mountain regions. When assessing the impacts of climatic change on mountain ecosystems and river basins whose origin lie in the Alps, one of the key controls on such systems will reside in changes in snow amount and duration. At present, regional climate models or statistical downscaling techniques, which are the principal methods applied to the derivation of climatic variables in a future, changing climate, do not provide adequate information at the scales required for investigations in which snow is playing a major role. A study has thus been undertaken on the behavior of snow in the Swiss Alps, in particular the duration of the seasonal snow-pack, on the basis of observational data from a number of Swiss climatological stations. It is seen that there is a distinct link between snow-cover duration and height (i.e., temperature), and that this link has a specific "signature" according to the type of winter. Milder winters are associated with higher precipitation levels than colder winters, but with more solid precipitation at elevations exceeding 1,700 - 2,000 m above sea-level, and more liquid precipitation below. These results can be combined within a single diagram, linking winter minimum temperature, winter precipitation, and snow-cover duration. The resulting contour surfaces can then be used to assess the manner in which the length of the snow-season may change according to specified shifts in temperature and precipitation. While the technique is clearly empirical, it can be combined with regional climate model information to provide a useful estimate of the length of the snow season with snow cover, for various climate-impacts studies.
\end{abstract}

\section{Introduction}

Snow is an essential component of earth system physics, both at high altitudes and at high latitudes, and any changes in the amount, duration, and timing of the snow-pack can have longlasting environmental and economic consequences. Snow determines the timing of peak river discharge during the melting of the snow-pack in the spring and, in many instances, maintains river flows even during warm and dry summer periods. In terms of ecosystems, snow cover protects dormant plants during the coldest part of the year from damaging frosts; for many plants, snow melt represents a signal for plants to begin their growth cycle (e.g., Keller et al. (1999). Körner (1994), for example, has shown that for mountain regions, the length of the snow season and minimum temperatures are the most important factors for high alpine vegetation because they determine the growth and survival rates of numerous species at high altitudes. Furthermore, and especially in the Alps, snow is intimately linked to tourism based on winter sports, on which numerous mountain resorts depend for a substantial part of their income (Beniston, 2000).

The two principal determinants of snow are temperature and precipitation; as climate changes, subsequently modifying temperature distributions and precipitation patterns, so does snow amount and duration. The succession of assessment reports of the Intergovernmental Panel on Climate Change (IPCC, 1990; 1996; 2001) have re-iterated with increasing confidence the fact that climate is changing as a result of the significant increases of greenhouse-gases in the atmosphere resulting 
from human activities. This trend is projected by the IPCC to accelerate in the course of the $21^{\text {st }}$ century, leading to a warming of $1.5-5.8^{\circ} \mathrm{C}$ on a global average by 2100 , with a "best-estimate" of $2.5^{\circ} \mathrm{C}$ (IPCC, 2001). In mountain regions, an average rise of $1^{\circ} \mathrm{C}$ is accompanied by a general rise of about $150 \mathrm{~m}$ in the altitude of the snowline (Haeberli and Beniston, 1998). Regional studies of climatic change in Switzerland (Marinucci et al., 1995; Beniston et al., 1996; Rotach et al., 1997; Maisch, 1998) suggest that Alpine temperatures could rise by as much as $3^{\circ} \mathrm{C}$ by 2050 , with possibly increased precipitation in winter but a substantial decrease in summer. For the Swiss Alps, a warming of this amplitude would push the snowline upward by at least $400 \mathrm{~m}$ in winter. This implies that the surface area with a significant winter snow pack could be reduced from an average of 18,000 $\mathrm{km}^{2}$ currently (Baumgartner and Apfl, 1994) to less than $14,000 \mathrm{~km}^{2}$ by 2050 , i.e., a reduction in snow-covered surfaces of close to $25 \%$. Results from other investigations confirm the high sensitivity of snow pack and duration to climate variability (e.g., Cayan, 1996) and observed $20^{\text {th }}$ Century warming (e.g., Karl et al., 1993a; Dettinger et al., 2002).

It therefore seems appropriate, in view of the central role snow plays in many natural and economic systems, to assess the changes that could intervene in the mountain snow-pack in a changing global climate. At present, however, it is difficult to quantify with any precision the possible changes that may intervene in the Alpine snow-pack in coming decades. Orographic precipitation in general, and snowfall in particular, are among the most difficult variables to simulate in climate models, even at the high spatial and temporal resolutions of current regional climate models (Giorgi and Mearns, 1991). Some attempts to address this problem have been undertaken on the basis of statistical downscaling techniques (Gyalistras et al., 1994; Zorita and von Storch, 1999, for example), with limited results. Snowmelt models have been developed (e.g., Martinec et al., 1983) for use in hydrological runoff modeling systems, and tested in numerous geographical and climatic regions (e.g., Rango, 1992). However, these models have no predictive capability, as they are based on observation and use Geographic Information Systems (GIS) techniques that link snowmelt to runoff.

More recently, Martin et al. (1994) have developed a statistical snow model in a computer-based expert system, and incorporated this to the French general circulation climate model ARPEGE. Interesting results on future snow-pack trends in the French Alps were reported by Martin and Durand (1998). However, this system has a number of limitations in its long-term predictive capabilities, as the authors themselves point out.

It is thus unfortunate that the future evolution of a key parameter capable of exerting major controls on numerous of elements of the earth system cannot be accurately predicted for the time being, particularly at the scales required by the climate-impacts community. One possible manner of addressing the issue of snow-pack duration resides in an approach that is based on a statistical and historical analysis of snow in the Swiss Alps. The behavior of snow as a function of temperature, precipitation, and altitude for a number of Swiss climatological sites will be discussed in this paper, with a view of establishing a temperature-precipitation matrix upon which snow cover is superimposed. It will be seen that this matrix can be applied not only to current but also to future climatic conditions, at the very local scales required for ecological and hydrological impacts studies. It should be emphasized, however, that this is a first attempt to address such issues and will need substantial refinement in the future in order to be more widely applicable to climate impacts studies.

\section{Particularities of the Alpine snow-pack in the $20^{\text {th }}$ century}

\subsection{Data sets used}


Human perception of climatic events such as the frequency of "white Christmas" or the fact that "in the past, snow was more abundant than today" are biased by a relatively short collective memory. In addition, it is often the case that one particularly notable event (e.g., a severe snowstorm or an unusual accumulation of snow) triggers the perception that these events are the norm. Another popular belief is that there has been a shift in the seasonality of snow in the Alps, with the season beginning later in the year, but also ending later in the spring. A genuine shift in the timing of the snow season or a decrease in the quantity of snow would indeed have significant repercussions upon many natural and socio-economic systems. Indeed, if the general perception of stakeholders is based on misconceptions rather than on facts, then certain long-term economic or policy decisions (for example, regarding investments for ski-lift infrastructure) may be taken in an inappropriate manner.

In the present study, climatological data from the Swiss meteorological service, MeteoSwiss (Bantle, 1989) have been used. Figure 1 shows the location of the 18 observational sites in Switzerland that were used, where snow data is available in digital form since at least 1960 . These climatological stations span a range of altitudes from $300-2500 \mathrm{~m}$ above sea level, as given by the inset that shows the altitudinal distribution of the stations selected for this investigation.

It should be emphasized that the best available data has been used here, but that the quality of some of the information may be somewhat open to question, thus requiring caution in the data interpretation and analyses that follow. Raw data has been employed in the present study, principally because if similar studies were to be conducted elsewhere, to check the consistency of results with those reported here, it is unlikely that data from other regions would be homogenous. Over the years, site changes may have biased some of the results; for example, the Davos observing site has undergone a shift in geographical location in the 1970s, while the highelevation Säntis site is located at a mountain summit, where strong winds and nearby constructions may perturb the snow records. However, as will be seen later, the overall conclusions would not change significantly from those reported in this study, even if data were homogenous or if sites were free of site-specific characteristics that interfere with measurements. It may be further argued that there is a large heterogeneity in the geographic distribution of the measurement sites, with site-specific characteristics that would be capable of biasing climatological statistics. However, experience with the data has shown that, when considering medium to long-term averages, the local biases tend to be removed and the spatial heterogeneity is no longer an obstacle to considering data from the different observational sites simultaneously. Moreover, Jungo and Beniston (2001) have shown through cluster analysis that, despite individual site heterogeneity, there is a close resemblance between climatological variables in different parts of Switzerland, particularly on an altitudinal basis. Finally, the observational sites located on the southern slopes of the Swiss Alps facing Italy have not been considered in the present analysis. This is because the particular climatic regimes in this part of the Alpine chain are closely governed by Mediterranean influences. These have a distinctly different character to the regimes influencing the north of the Alps; Mediterranean air masses spill over only occasionally into the mountains themselves or to the lowlands north of the Alps.

Insert Figure 1 here

\subsection{Shifts in the snow season}

An example of the distribution of snow amount on a seasonal basis is given for the site of Arosa in Figure 2, which uses a Hövmoller-type rendering. The large variations in snow amount and 
duration exhibited in the diagram have been shown by Beniston (1997) to be closely linked to the behavior of the North Atlantic Oscillation (NAO). During strongly-positive phases of the NAO, the presence of persistent high pressure fields over the Alpine region from late fall well into the winter are accompanied by large positive temperature anomalies and low precipitation, both of which are unfavorable for seasonal snow accumulation. This implies that large-scale forcing, rather than just local or regional factors, plays a dominant role in controlling the timing and amount of snow in the Alps, as evidenced by the fluctuations illustrated in Figure 2. Since the mid-1980s and up till today, the length of the snow season and the snow amount, based on a 20$\mathrm{cm}$ threshold, have been reduced by $2-3$ weeks as a result of unusually high and persistent pressure over the Alps. This situation is associated with the highest positive anomalies of the NAO index recorded during the $20^{\text {th }}$ century. Part of the reduction in snow amount and duration is, in addition, the result of the significant warming that has taken place in the 1990s, as will be shown later. Figure 2 also shows that on the whole, however, the snow season in Arosa begins essentially towards the end of November and ends towards mid-May, even if the end of the season has been earlier in recent years. This relative constancy of the beginning and end of the season in Arosa, within \pm 2 weeks is principally linked to the cycle of direct solar energy; in late April and early May, solar energy is close to its annual peak and becomes the dominant factor in the snowmelt process.

The shift in the snow season, as frequently perceived by the general public, is thus not confirmed for this particular site; the snow season at such locations remains constrained principally between the limits that are highlighted by the dotted lines on the diagram. The quantities of snow, on the other hand, can and do vary widely from one year to another, as a result of shifts in precipitation patterns and distribution that can be partially attributed to the behavior of the NAO.

\section{Insert Figure 2 here}

\section{Insert Figure 3 here}

A closer investigation for a number of stations confirms the fact that the length of the snow season has tended to decrease at most locations since the early 1970s, as seen in Figure 3. However, the duration of continuous snow cover exceeding $10 \mathrm{~cm}$ exhibits high interannual variability; for example, at Château d'Oex in the western part of the Swiss Alps, snow cover with at least a 10-cm snow-pack ranges from 10 days in 1961/62 to 110 days the following year. Davos, on the other hand, exhibits generally the same duration of the snow season towards the end of the $20^{\text {th }}$ century as in the 1930s. One notable exception to the tendency towards a reduction in the length of the snow season is the high-altitude site of Säntis, in the north-eastern Swiss Alps, where snow has on average increased since the 1960s. As will be discussed later, the trends illustrated in Figure 3 are consistent with the tendency towards an increase of solid precipitation at high elevations, and an increase in liquid precipitation at low to medium elevations, as suggested by a number of studies related to global warming (Beniston et al., 1996; Martin and Durand, 1998; Parry, 2000). The altitudinal dependency of snow duration is also highlighted in this figure, and so is the synchronism of major events between the different stations, such as the lack of snow in 1961/62 or the peak snow amounts in 1968/69 and 1998/99. In other instances, however, the curves are out of phase, particularly between the lower-elevation sites and the set of three higher-elevation stations. This is a reflection of the fact that in some years, a certain proportion of precipitation falls as snow in Davos and Säntis, and as rain at lower elevations such as Château d'Oex. When taking longterm average values, however, there is a strong linear relation between snow duration and height for the 18 selected Swiss sites, as seen in Figure 4 (the correlation coefficient, $r=0.97$. The fact that most stations lie very close to the regression line, including the Säntis site that is subject to 
strong winds and interference by buildings close to the summit, give added confidence that the data used here is of sufficient quality and representativity for meaningful conclusions to be drawn.

\section{Insert Figure 4 here}

\section{Insert Figure 5 here}

Figure 5 provides additional information on the seasonal evolution of the snow-pack at three sites (Château d'Oex, Davos, and Säntis), averaged over the 1960s and the 1990s. It is observed that at the lower elevation site of Château d'Oex, the snow depth is reduced by $45 \%$ between the $1960 \mathrm{~s}$ and the 1990s, based on the figures for total seasonal snow accumulation. Much of the shortfall in snow amount occurs in the early part of the season, where snow does not accumulate as in earlier years as a result of warmer temperatures and the fact that when precipitation falls, it is more often in the form of rain than snow in the early winter. The snow season in Château d'Oex begins later and ends marginally earlier in the 1990s than in the 1960s. Over this same 30-year interval, Davos experiences a reduction of average total accumulation from $330 \mathrm{~cm}$ to $288 \mathrm{~cm}$, i.e., a loss of about $12 \%$ of snow depth. The beginning and end of the snow season at Davos are essentially the same in both periods, as already mentioned. At the high-elevation site of Säntis, however, the trend is reversed, both in terms of snow amount and duration of the snow-pack. Total accumulation over the season has increased from an average decadal-scale value of $1590 \mathrm{~cm}$ in the 1960 s to over $2475 \mathrm{~cm}$ in the 1990s, i.e., an enhancement of snow depth of $35 \%$.

In parallel, winter minimum temperatures (the average temperature for December, January, and February, or DJF) have increased significantly over this period, and in particular DJF temperature minima, which are an important determinant on snow amount and duration (Figure 6). In order to be able to compare the trends between stations, temperature anomalies have been plotted as a function of time using the 1961-1990 period as the climatological baseline and, for the sake of clarity, have been smoothed with a 5-year filter to remove the noisiness associated with interannual fluctuations. On a century-scale basis, based on simple linear regression analysis, the warming rates are all significant and range from $1.8^{\circ} \mathrm{C} /$ century in Neuchâtel to $3.7^{\circ} \mathrm{C} /$ century at the summit of Säntis. Since the late 1980s, minimum temperatures have systematically remained above their long-term mean values at all stations. The general rise of winter minimum temperatures began in the early to mid-1960s at all sites, and underwent a cooling in the early to mid-1980s before warming rapidly since. In the case of Säntis, however, DJF minima entered the positive anomaly range in the early 1970s and have never reverted to cooler-than-average conditions since, even though there is a relative cooling as at the other sites in the 1980s. The strong trends in minimum temperatures have been reported in the literature, notably by Karl et al. (1993b) for Northern Hemisphere observations, and by Jungo and Beniston (2001) for Switzerland. Furthermore, the increasing temperature trends with height were first reported by Beniston and Rebetez (1996) and later confirmed through modeling studies by Giorgi et al. (1997).

\section{Insert Figure 6 here}

\section{Insert Figure 7 here}

The DJF precipitation anomalies, on the other hand, contain much more statistical noise than the corresponding minimum temperature anomalies even when smoothed with a 5-year filter, as can be ascertained from Figure 7. By far the most outstanding increase and overall positive winter precipitation anomaly, with respect to the 1961-1990 reference period, is to be found at Säntis, with a century-scale increase of $3.3 \mathrm{~mm} /$ day; this is close to a doubling of precipitation during the 
$20^{\text {th }}$ century. Since the mid-1980s, the precipitation anomalies have been consistently positive. Other sites do not exhibit any particularly significant trends; some show an overall decrease, especially in the 1990s, others a modest rise that may be due more to the fluctuating nature of the signal rather than to any significant trend. Although the rise in temperature and precipitation are both most pronounced at Säntis, it is difficult to affirm that this combined increase is indeed related to the observed $20^{\text {th }}$ century warming and a consequent enhancement of the hydrological cycle. However, this considerable increase of high-elevation precipitation in an environment where temperatures remain below the freezing point (despite the general rise in temperature since the 1960s), explains much of the change in the snow-pack statistics at Säntis compared to lower elevations. At the lower-level sites, warmer conditions have substantially reduced the number of days with minima below the freezing point.

\subsection{Behavior of the snow-pack as a function of type of winter}

In order to investigate more closely the behavior of snow in terms of different mean winter conditions, the 5 ("cold"), 50 ("average") and 95 ("mild") percentiles of the DJF minimum temperature distributions have been selected. Figure 8 shows the manner in which precipitation changes with height according to cold, average, or mild winters. The general increase with height is seen in all three sets of data, but the precipitation-height gradient is considerably enhanced when progressing from cold to mild winters. This implies that precipitation is more abundant during warm winters than during average or cold winters, and furthermore, that the precipitation excess increases with height. For example, at an altitude of $1,000 \mathrm{~m}$, average daily winter precipitation ranges from $1.5 \mathrm{~mm} /$ day during cold conditions to $4.5 \mathrm{~mm} /$ day during warm conditions, i.e., an average range of $3 \mathrm{~mm} /$ day. At 2,500 m, the respective amounts are 4.5 and $11.0 \mathrm{~mm} /$ day, i.e., an average range of $6.5 \mathrm{~mm} /$ day.

\section{Insert Figure 8 here}

This changing characteristics of precipitation have obvious repercussions on the amount and duration of snow in the Alps. Using the same definitions for cold, average, and mild winters, Figure 9 illustrates the manner in which snow duration changes with height as a function of the type of winter. At low to medium elevations, below about 1,500 m above sea level, mild winters are accompanied by reduced snow amounts and duration, while the reverse is true for cold winters, because of the transition from liquid to solid precipitation at these altitudes. However, at elevations above $2,000 \mathrm{~m}$, the more abundant precipitation associated with mild winters falls as snow and in much larger amounts than during cold winters. At an altitude of 1,000 m, there is are on average about 135 days with continuous snow cover during cold winters, but only 65 during mild winters. The respective figures at 2,500 m altitude are 250 and 350 days, bearing in mind the caveats related to the quality and representativity of the data set at such a high elevation site.

\section{Insert Figure 9 here}

The results discussed here can be used as an analogy to what may happen in a warmer climate. The statistics lend some credence to speculation that warmer conditions in the Alps, associated with enhanced precipitation, are likely to lead to more abundant snowfall in the higher reaches of the mountains, but much reduced snow at lower levels where precipitation is more likely to fall in the form of rain. From the statistics outlined in previous paragraphs, the "crossover" level where snow becomes more abundant under milder conditions is located between 1,700 and 2,000 m above sea level. This result is closely related to a previous study by Beniston (1997), where it was seen that above about 1,700 $\mathrm{m}$ in the Swiss Alps, there has been little significant change in snow 
variability, i.e., whether under warm or cold winter conditions, there is always snow on the ground throughout the winter season, whatever the depth of the snow-pack. 


\subsection{A snow matrix to describe the range and shifts of snow duration}

The relationship between mean winter minimum temperature, precipitation, and snow duration can be graphically summarized, for all the climatological sites studied, in the two-dimensional plot given in Figure 10, where the abscissa is the DJF mean minimum temperature and the ordinate DJF mean daily precipitation. The 2-D surfaces represent the snow-cover duration, with a contour interval of 25 days. Figure 10 suggests a dominant influence of temperature on snow duration, with small shifts in mean winter temperature leading to substantial changes in the length of the season. There is also a secondary influence of precipitation amount on snow duration, where for a given temperature, snow duration changes according to the amount of precipitation.

For a given winter mode (i.e., “cold”, “average”, or "mild”), any displacement within the contour surfaces is associated with altitudinal shifts, i.e., moving up or down the temperature scale is essentially analogous to moving up or down height levels in the mountains. On the other hand, displacement within these surfaces can also be related to warmer or cooler, wetter or drier climatic conditions. As a result, this type of diagram can be used empirically to estimate, for a particular site, the changes in snow duration that may occur under shifting climatic conditions. As an example, the high-altitude Säntis site (2,500 $\mathrm{m}$ above sea level) is characterized in this diagram by a long-term mean DJF minimum temperature of $-7.1^{\circ} \mathrm{C}$ and precipitation of $6.3 \mathrm{~mm} /$ day, with a corresponding average snow-cover duration of close to 300 days. A rise of mean winter minima of $2^{\circ} \mathrm{C}$ with no change in precipitation would lead to a 50-day reduction of the snow season (250 days in total at $-5^{\circ} \mathrm{C}$ ). With such a rate of warming, precipitation would need to increase from the current average of $6.8 \mathrm{~mm} /$ day to over $10 \mathrm{~mm} /$ day, i.e., almost a $50 \%$ increase, in order to maintain the current number of days with continuous snow cover. Such an increase is plausible, as seen in the previous discussion pertaining to precipitation/height relationships under differing winter conditions; furthermore, certain climate model results (e.g., Rotach et al., 1997) for the Alpine region suggest a significant rise in winter precipitation. At lower elevations, such as Arosa (about $700 \mathrm{~m}$ lower in elevation than Säntis), long-term DJF minimum temperature is $-2.2^{\circ} \mathrm{C}$ and precipitation is $3.1 \mathrm{~mm} /$ day, with a corresponding 140 days of continuous snow cover. A rise in temperature of $2^{\circ} \mathrm{C}$ without any precipitation change would result in a reduction in seasonal snow cover down to about 90 days in total. A $50 \%$ increase in precipitation with the same $2^{\circ} \mathrm{C}$ increase would to some extent compensate for the temperature rise; in this case, winter snow-pack duration in Arosa would be roughly 110 days.

The empirical analysis outlined here has been constructed on the basis of the long-term averages of the variables considered, and focuses on a number of sites that span a significant altitudinal range. This approach was already suggested by Whetton et al. (1992), but for a single site in Australia; the advantage of the present study is that the snow-duration statistics could have a much wider range of applicability.

The ellipses in Figure 10 show the spread of temperature and precipitation on the basis of their $2 \sigma$ (standard deviation) levels around the mean value, located at the center of the ellipse. The inclination of the ellipses are functions of the covariance between temperature and precipitation. It is seen that at Engelberg, for example, snow duration currently ranges from 80 days to 160 days with a $2 \sigma$ temperature spread of almost $3^{\circ} \mathrm{C}$. The current $2 \sigma$ range of precipitation, from 2.1 to 3.8 $\mathrm{mm}$ /day does not exert such a strong influence on the duration of snow-cover; for example, this increases from 120 to 130 days if the mean minimum DJF temperature is held constant at $-2^{\circ} \mathrm{C}$.

Figure 10 thus emphasizes an additional problem related to estimating changes in snow cover duration under changing climatic conditions, namely the fact that already under current climatic 
conditions, the year-to-year variability of the snow-pack is extremely high. The contour surfaces provided in Figures 10 may certainly be of value in estimating changes in average snow duration as a function of shifts in winter temperature and precipitation. However, it would also be important to assess the possible future changes in the extreme range of snow duration, represented by the ellipses of Figure 10. In order to make the best possible use of these diagrams, information from regional climate models would thus need to include not only the average changes of temperature and precipitation with height, thereby allowing to use the 2-D plots to estimate decreases or increases in snow-cover duration at particular heights or locations, but also the statistical spread of temperature and precipitation in a changing climate.

\section{Concluding remarks}

The present study has shown that, while year-to-year variability in snow cover in the Alps is high, the long-term average climatic conditions have favored a longer snow season at high elevations (i.e., 2,000 $\mathrm{m}$ above sea-level and higher) that at lower elevations during the course of the $20^{\text {th }}$ century. One reason for this is that milder winters are associated with increased precipitation that falls as snow at high elevations but as rain at lower altitudes. The relationship between the length of the snow season and mean winter temperature and precipitation allow the construction of contour surfaces that can be used to assess changes in snow duration as a function of shifts in both temperature and precipitation. Any changes to one or both of these parameters can lead to substantial changes in snow duration. The contour surfaces exhibited in Figures 10 enable an empirical assessment of how snow may change in the future, if the fundamental changes in winter temperature and precipitation are known, for example on the basis of regional climate model simulations or from statistical downscaling techniques. The resulting information can then be used in climate-impacts studies for systems that are highly dependent on, or sensitive to, snow amount and duration. Greater confidence in the applicability of such a matrix would emerge from the use of much more homogenous data, and data from locations that are less biased because of local site conditions. In order to account for the non-linear behavior of the relationship between snow amount and temperature and precipitation, future refinements could include the application of a more advanced statistical treatment to account for these non-linearities.

Although the method discussed in the previous section is relatively simple to apply, it is not without problems, however. In particular, it is necessary to take into account not only the changes in average climatic conditions, but also their statistical range. This is because, according to the location in the 2-D contour diagram (Figure 10), even small changes in precipitation or temperature can lead to large changes in snow-pack duration. The possible range of precipitation and temperature can be supplied by regional climate models, provided they simulate a sufficient number of situations to capture the strong year-to-year variability that snow amount and duration exhibits.

Work is currently under way to apply a surface energy balance model, that implements a snow parameterization scheme, to the types of situations discussed in this paper. The objective of the model, after validation against observational data as provided in the present paper, is to provide deeper insight into the mechanisms of change and to point to the probable "direction" of future temperature and precipitation change in the 2-D surfaces of Figure 10. The possibilities offered by such a model are to complement the empirical type of approach related to the temperatureprecipitation-snow duration matrix, and to explain some of the physical mechanisms that govern the behavior of the alpine snow-pack. 


\section{References}

Bantle, H., 1989: Programmdokumentation Klima-Datenbank am RZ-ETH Zürich, Swiss Meteorological Institute, Zürich.

Baumgartner, M.F., and G. Apfl, 1994: Monitoring snow cover variations in the Alps using the Alpine Snow Cover Analysis System (ASCAS), Mountain Environments in Changing Climates, M. Beniston,(ed.), Routledge Publishing Company, London and New York, 108-120.

Beniston, M., 1997: Variations of snow depth and duration in the Swiss Alps over the last 50 years: links to changes in large-scale climatic forcings. Climatic Change, 36, 281 - 300

Beniston, M., 2000: Environmental Change in Mountains and Uplands. Arnold/Hodder and Stoughton/Chapman and Hall Publishers, London, UK, and Oxford University Press, New York, USA. 172 pp.

Beniston, M., and Rebetez, M., 1996: Regional behavior of minimum temperatures in Switzerland for the period 1979 - 1993. Theor. and Appl. Clim. 53, 231 - 243

Beniston, M., Fox, D. G., Adhikary, S., Andressen, R., Guisan, A., Holten, J., Innes, J., Maitima, J., Price, M., and Tessier, L., 1996: The Impacts of Climate Change on Mountain Regions. Second Assessment Report of the Intergovernmental Panel on Climate Change (IPCC), Chapter 5, Cambridge University Press, pp. 191 - 213

Cayan, D. R., 1996 : Interannual climate variability and snow-pack in the Western United States. Journal of Climate, 9, 928-948

Dettinger, M.D., Cayan, D.R., Diaz, H.F., and Stewart, I., 2002: Variations and trends in snowmelt and streamflow timing; global and North American patterns in the $20^{\text {th }}$ century. Climatic Change, in preparation

Giorgi, F. and Mearns, L.O., 1991: Approaches to the simulation of regional climate change: a review. Reviews of Geophysics, 29: 191-216.

Giorgi, F., Hurrell, J., Marinucci, M., and Beniston, M., 1997: Height dependency of the North Atlantic Oscillation Index. Observational and model studies. J. Clim., 10, 288 - 296

Gyalistras, D., von Storch, H., Fischlin, A., and Beniston, M., 1994: Linking GCM-Simulated Climatic Changes to Ecosystem Models: Case Studies of Statistical Downscaling in the Alps. Clim. Res., 4, 167 - 189

Haeberli, W., and Beniston, M., 1998: Climate change and its impacts on glaciers and permafrost in the Alps. Ambio, 27, $258-265$

IPCC, 1990: Climate Change. The Intergovernmental Panel on Climate Change Scientific Assessment (Houghton, J., Callander, B., and Varney, S., eds.). Cambridge University Press, Cambridge and New York.

IPCC, 1996: Climate Change. The IPCC Second Assessment Report. Volumes I (Science), II (Impacts) and III (Socio-economic implications). Cambridge University Press, Cambridge and New York.

IPCC, 2001: Climate Change. The IPCC Third Assessment Report. Volumes I (Science), II (Impacts and Adaptation) and III (Mitigation Strategies). Cambridge University Press, Cambridge and New York.

Jungo, P., and Beniston, M., 2001: Changes in the anomalies of extreme temperatures in the 20th Century at Swiss climatological stations located at different latitudes and altitudes. Theor. and Appl. Clim., 69, 1-12

Karl, T. R., Groisman, P. Y., Knight, R. W., and Heim, R. R., 1993a : Recent variations of snow cover and snowfall in North America and their relation to precipitation and temperature variations. Journal of Climate, 6, 1327-1344.

Karl, T. R., Jones, P. D., Knight, R. W., Kukla, G., Plummer, N., Razuvayev, V., Gallo, K. P., Lindseay, J., Charlson, R. J., and Peterson, T. C., 1993b: Asymmetric trends of daily maximum and minimum temperature. Bull. American Meteorol. Soc., 74, 1007-1023 
Keller, F., Kienast, F., and Beniston, M., 2000: Evidence of the response of vegetation to environmental change at high elevation sites in the Swiss Alps. Regional Env. Change, 2, 7077

Körner, C., 1994: Impact of atmospheric changes on high mountain vegetation. In: Beniston, M. (ed.), Mountain environments in changing climates. Routledge Publishing Company, London and New York, pp. 155-166

Maisch, M., 1998 : Die Gletscher der Schweizer Alpen. VdF Publishers, Zurich, 378 pp.

Marinucci, M. R., Giorgi, F., Beniston, M., Wild, M., Tschuck, P., and Bernasconi, A., 1995: High resolution simulations of January and July climate over the Western Alpine region with a nested regional modeling system. Theor. and Appl. Clim., 51, 119 - 138

Martin, E., Brun, E., and Durand, Y., 1994 : Sensitivity of the French Alps snow cover to the variation of climatic variables. Annales Geophysicae, 12, 469-477.

Martin, E., and Durand, Y., 1998: Precipitation and snow cover variability in the French Alps. In: Beniston, M., and Innes, J. L. (Eds.), The Impacts of Climate Change on Forests, SpringerVerlag, Heidelberg/New York, pp. 81-92

Martinec, J., Rango, A., and Major, E., 1983: The Snowmelt Runoff Model (SRM) User's Manual. NASA Reference Publication 1100, Scientific and Technical Information Branch

Parry, M. L. (ed.), 2000 : Assessment of potential effects and adaptations for Climate Change in Europe : The ACACIA Report. Jackson Environment Institute Publications, Norwich, and European Commission Publications, Brussels. 350 pp.

Rango, A., 1992: Worldwide testing of the Snowmelt Runoff Model with applications for predicting the effects of climatic change. Nordic Hydrology, 23, 155-172

Rotach, M., Wild, M., Tschuck, P., Beniston, M., and Marinucci, M. R., 1996: A double $\mathrm{CO}_{2}$ experiment over the Alpine region with a nested GCM-LAM modeling approach. Theor. and Appl. Clim., 57, 209-227.

Whetton, P. H., Hennessy, K. J., Pittock, A. B., Fowler, A. M., and Mitchell, C. D., 1992 : Regional impact of the enhanced greenhouse effect on Victoria. CSIRO Division of Atmospheric Research Annual Report 1991-1992. Commonwealth Scientific and Industrial Research Organisation, Mordialloc, 64 pp.

Zorita, E. and H. von Storch, 1999: The analog method - a simple statistical downscaling technique: comparison with more complicated methods. J. Climate 12: 2474-2489 


\section{Figure captions}

Figure 1: Map of Switzerland showing the location of the 18 climatological observing sites used in this study. The inset shows the altitudinal distribution of the 18 sites, for $500 \mathrm{~m}$ intervals ranging from 500 to $2,500 \mathrm{~m}$ above sea-level.

Figure 2: Hövmöller-type diagram illustrating the seasonal distribution of snow amount in Arosa (1,846 $\mathrm{m}$ above sea level) from 1949-2000. The diagram allows a monthly representation of the quantities of snow over a long time-period.

Figure 3: Time series of the duration of the snow season for a number of Swiss observing sites located at different altitudes.

Figure 4: Relationship between mean (i.e., 30-year average of the 1961-1990 period) snow-cover duration and height for the observing sites considered.

Figure 5: Seasonal evolution of snow cover at Château d'Oex (980 m above sea level), Davos $(1,590 \mathrm{~m})$ and Säntis $(2,500 \mathrm{~m})$ averaged for the decade of the 1960s and that of the 1990s. The left-hand ordinate is scaled for Säntis, while the right-hand ordinate is scaled for Château d'Oex and Davos (a factor of 5 between the two sets of scales), in order to increase the resolution of the latter two curves.

Figure 6: Time-series of winter (December, January and February, or DJF) minimum temperature anomalies for several sites located at different altitudes.

Figure 7: As Figure 6, except for precipitation anomalies.

Figure 8: Precipitation changes with height for “cold” (5-percentile), “average” (50-percentile) and "mild" (95-percentile) winters.

Figure 9: As Figure 8, except for snow-cover duration.

Figure 10: 2-D contour surfaces of snow-cover duration as a function of winter (DJF) minimum temperature and precipitation for all selected climatological sites; ellipses show the $2 \sigma$ range of DJF minimum temperature and precipitation, and corresponding spread of snow-cover duration for Engelberg, Arosa, and Säntis. The slopes of the ellipses are related to the covariance of temperature and precipitation. 
Figure 1

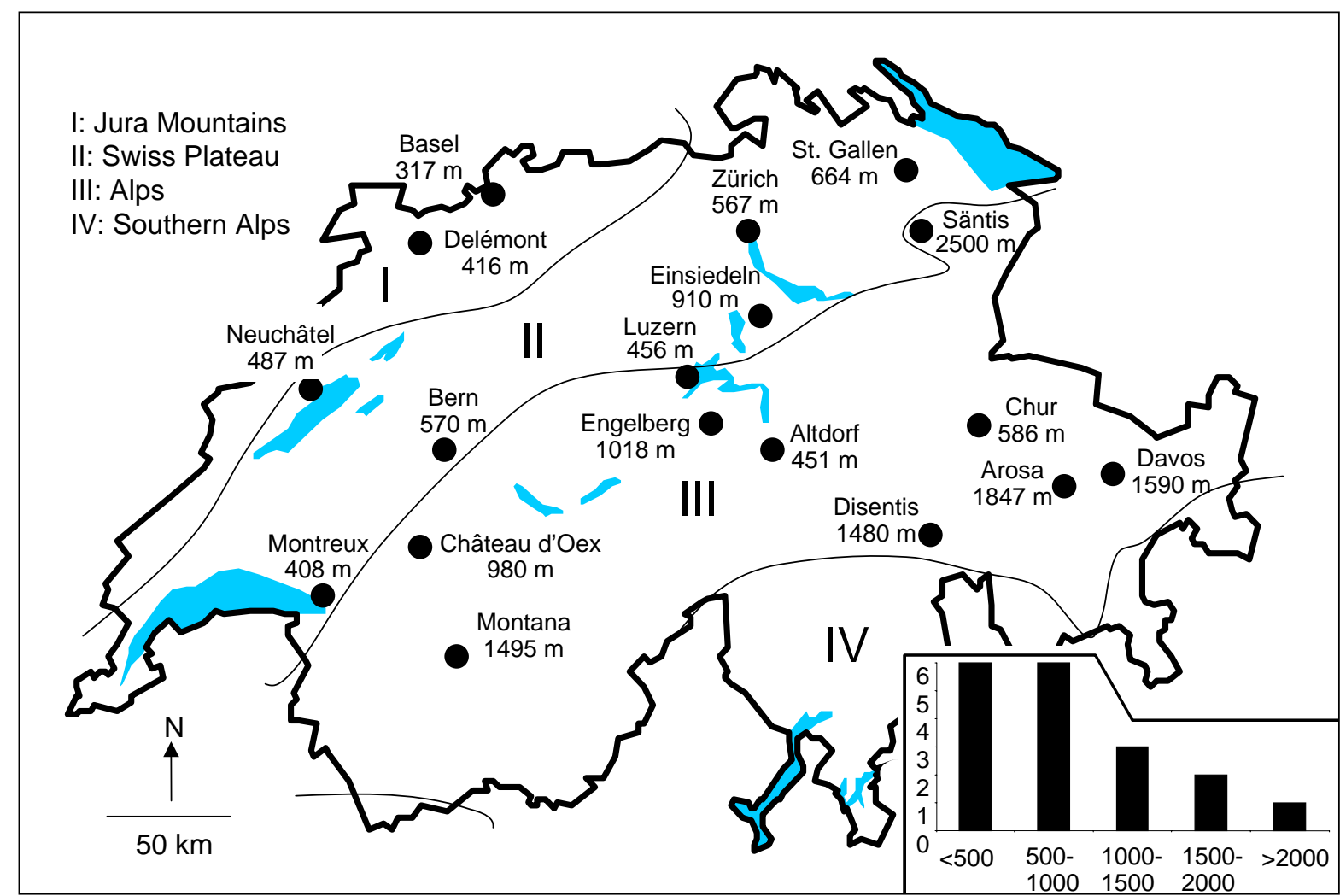


Figure 2

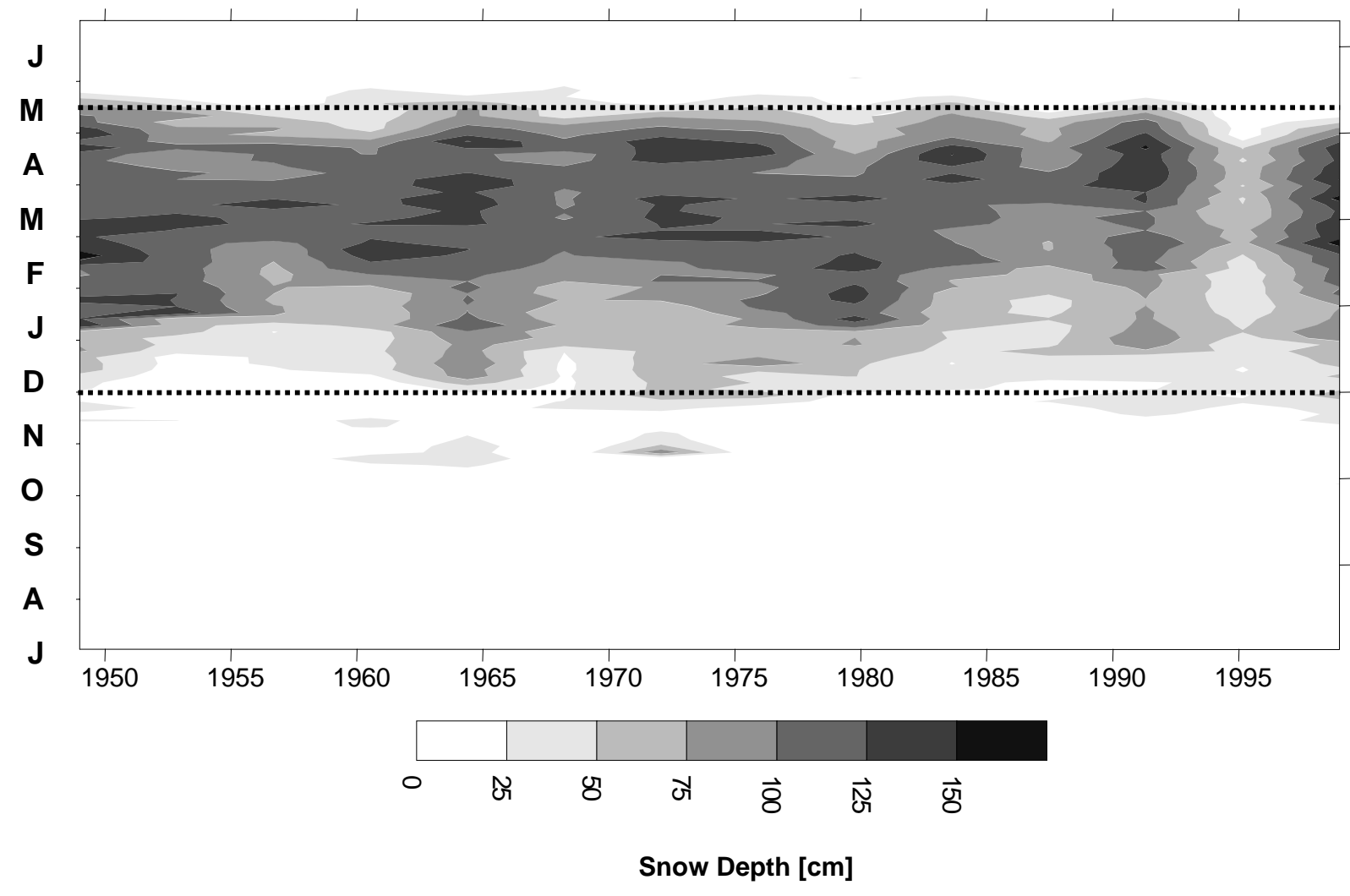


Figure 3

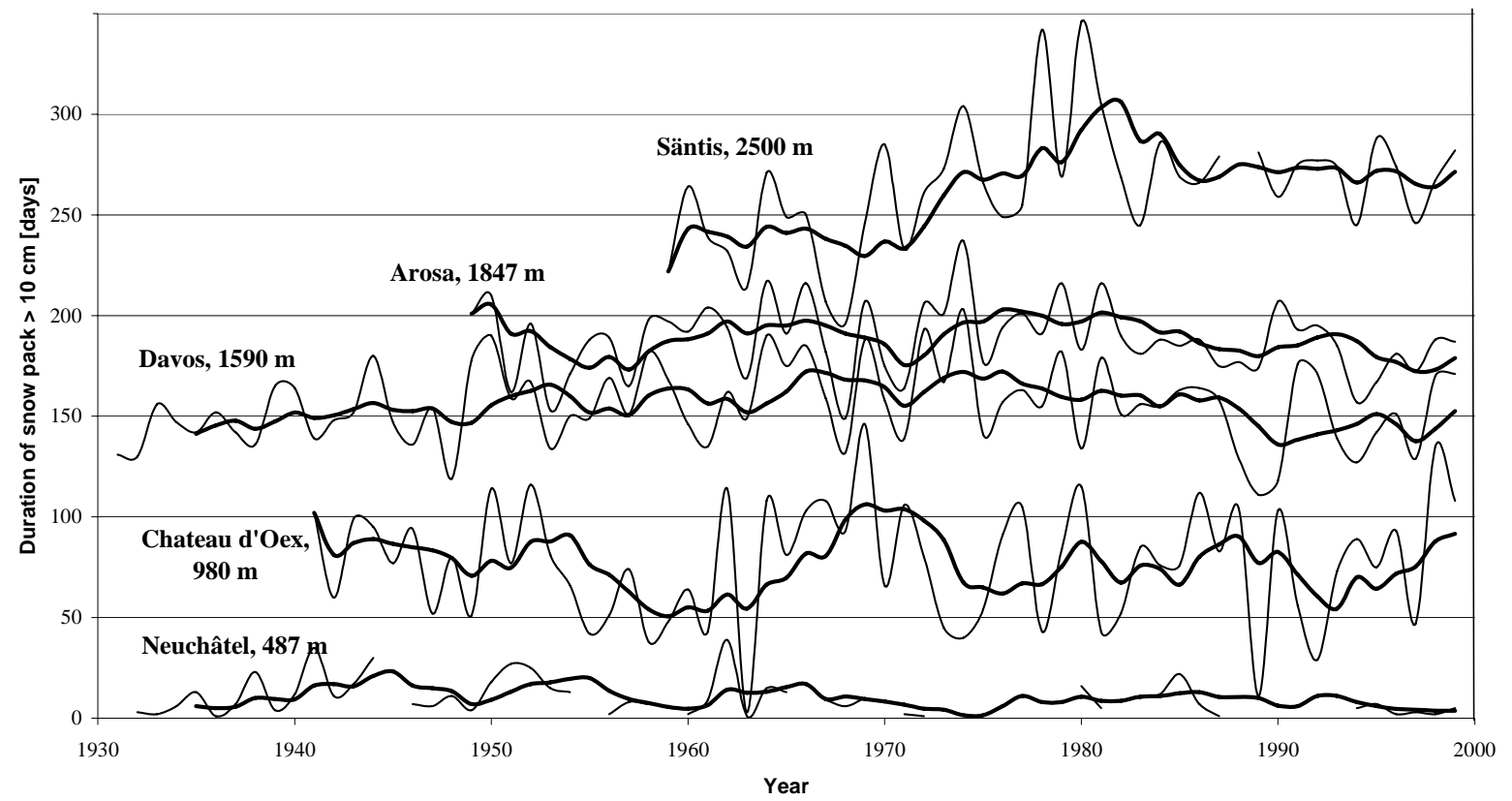


Figure 4

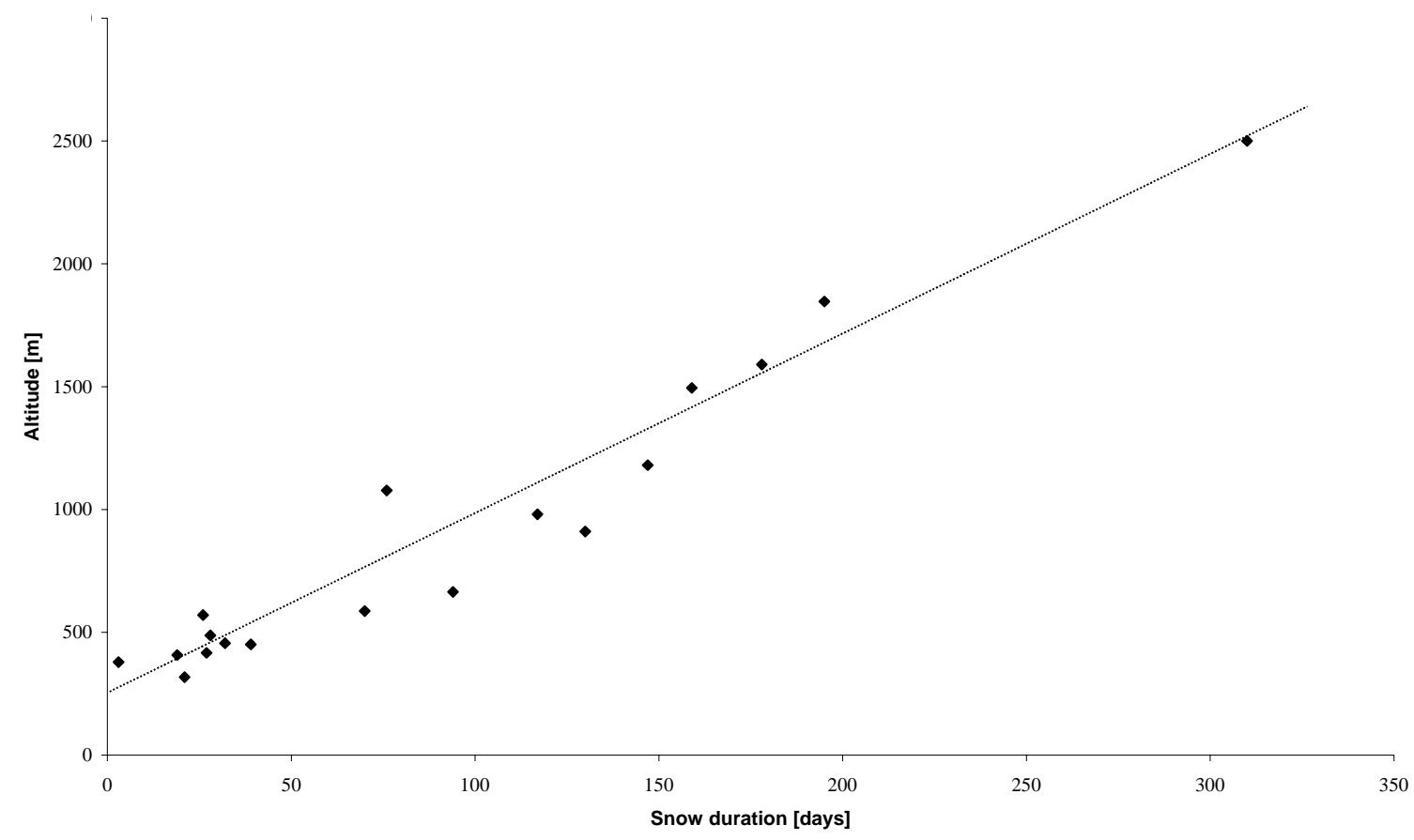


Figure 5

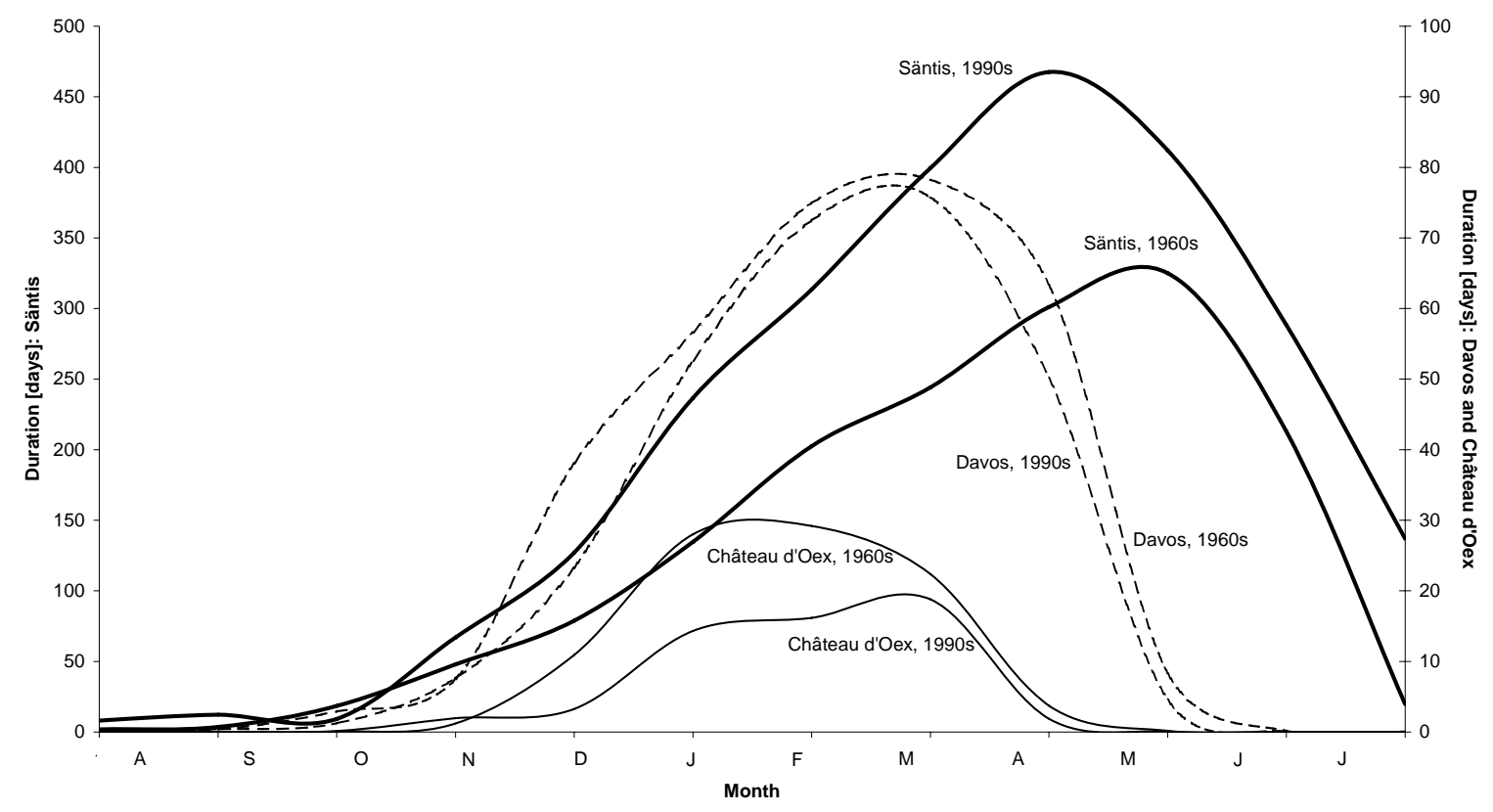


Figure 6

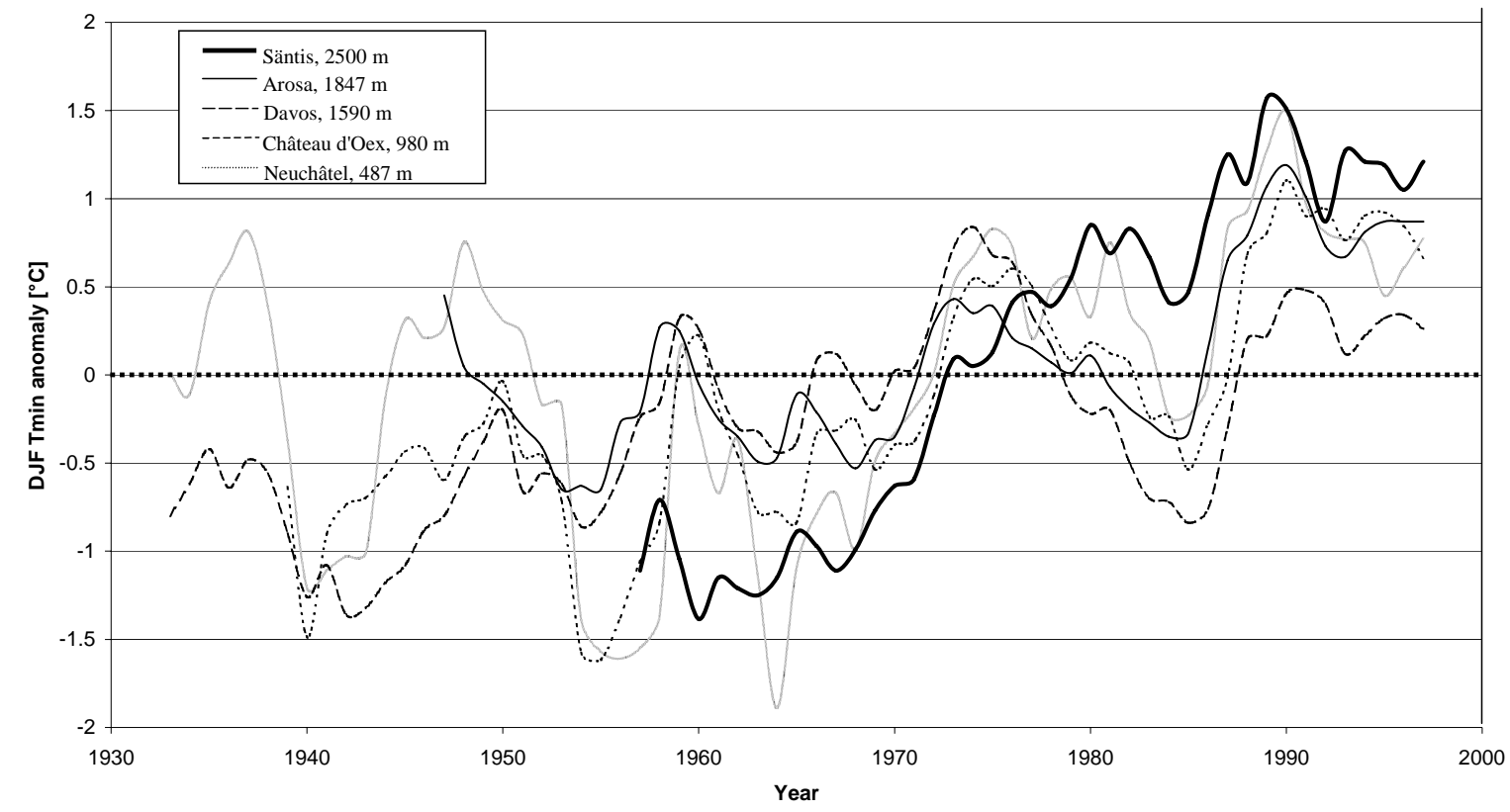


Figure 7

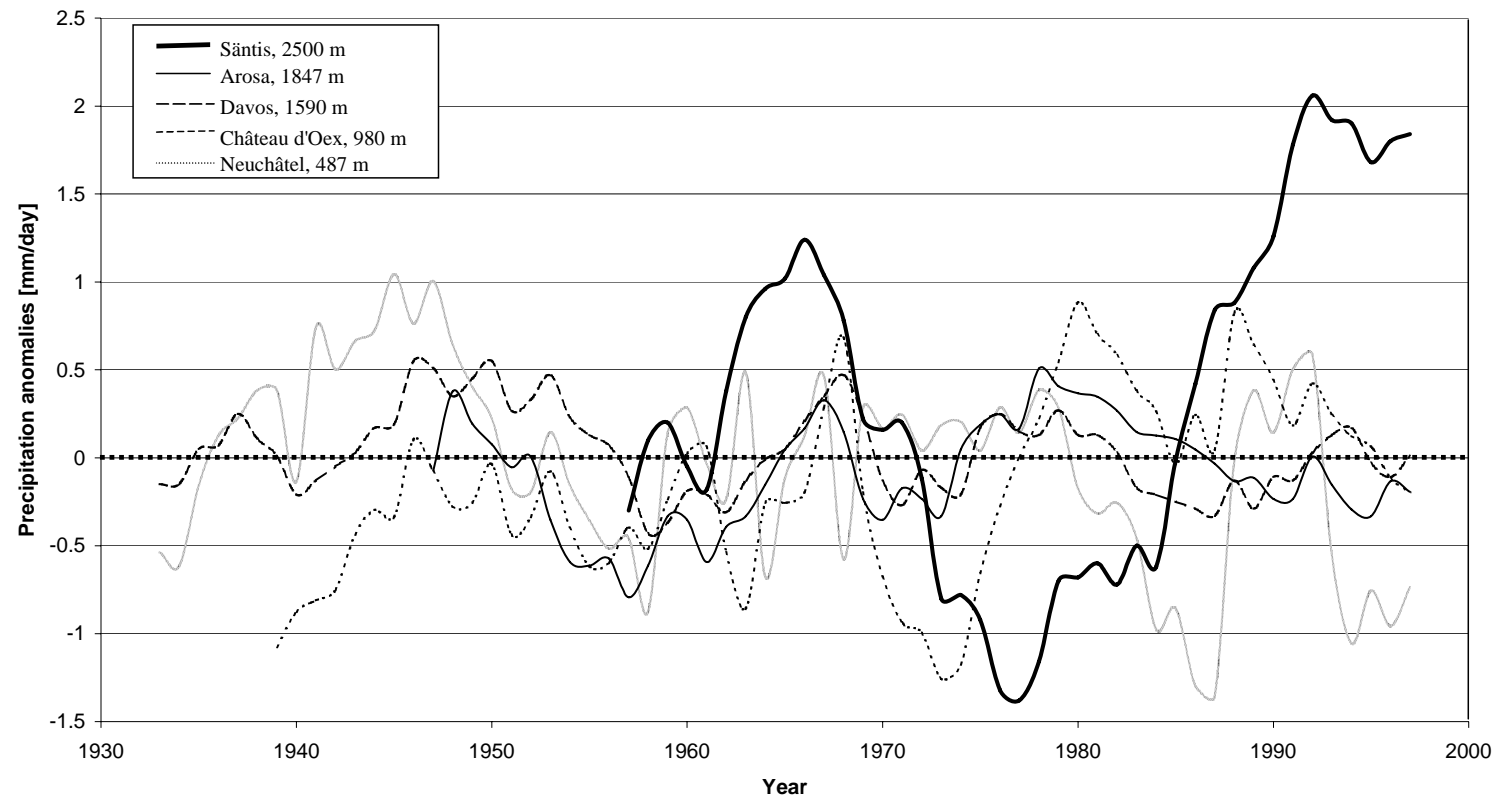




\section{Figure 8}

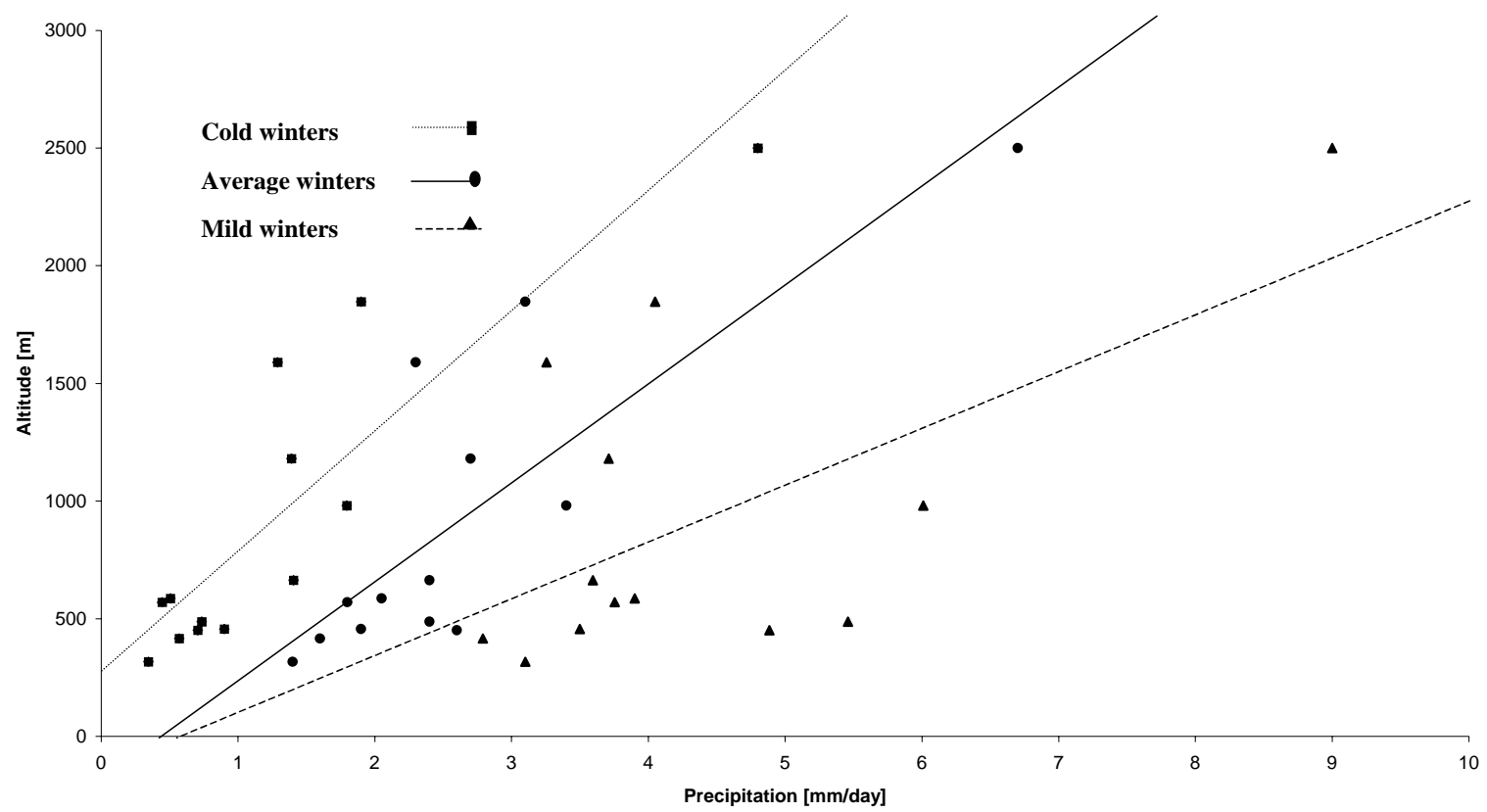




\section{Figure 9}

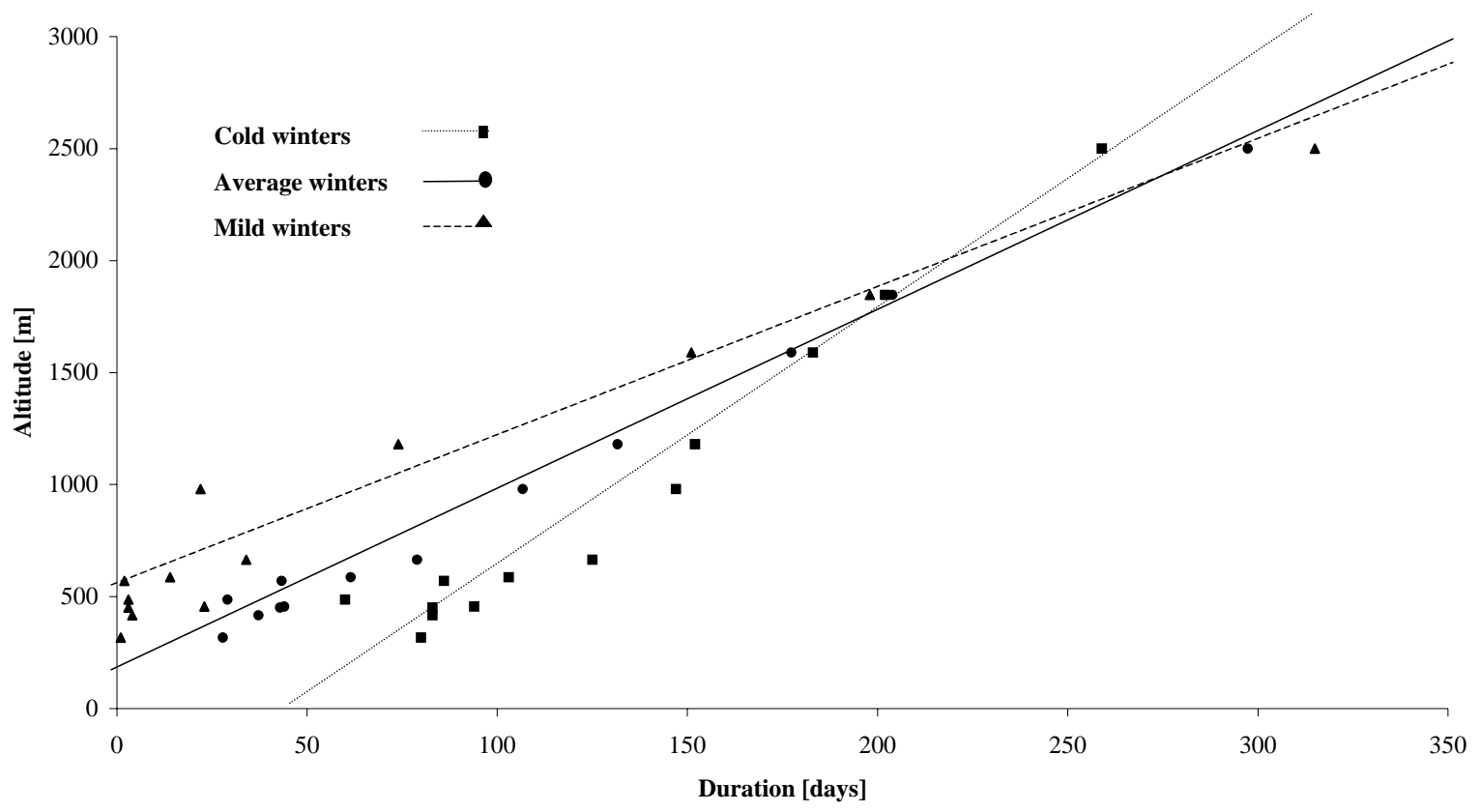


Figure 10

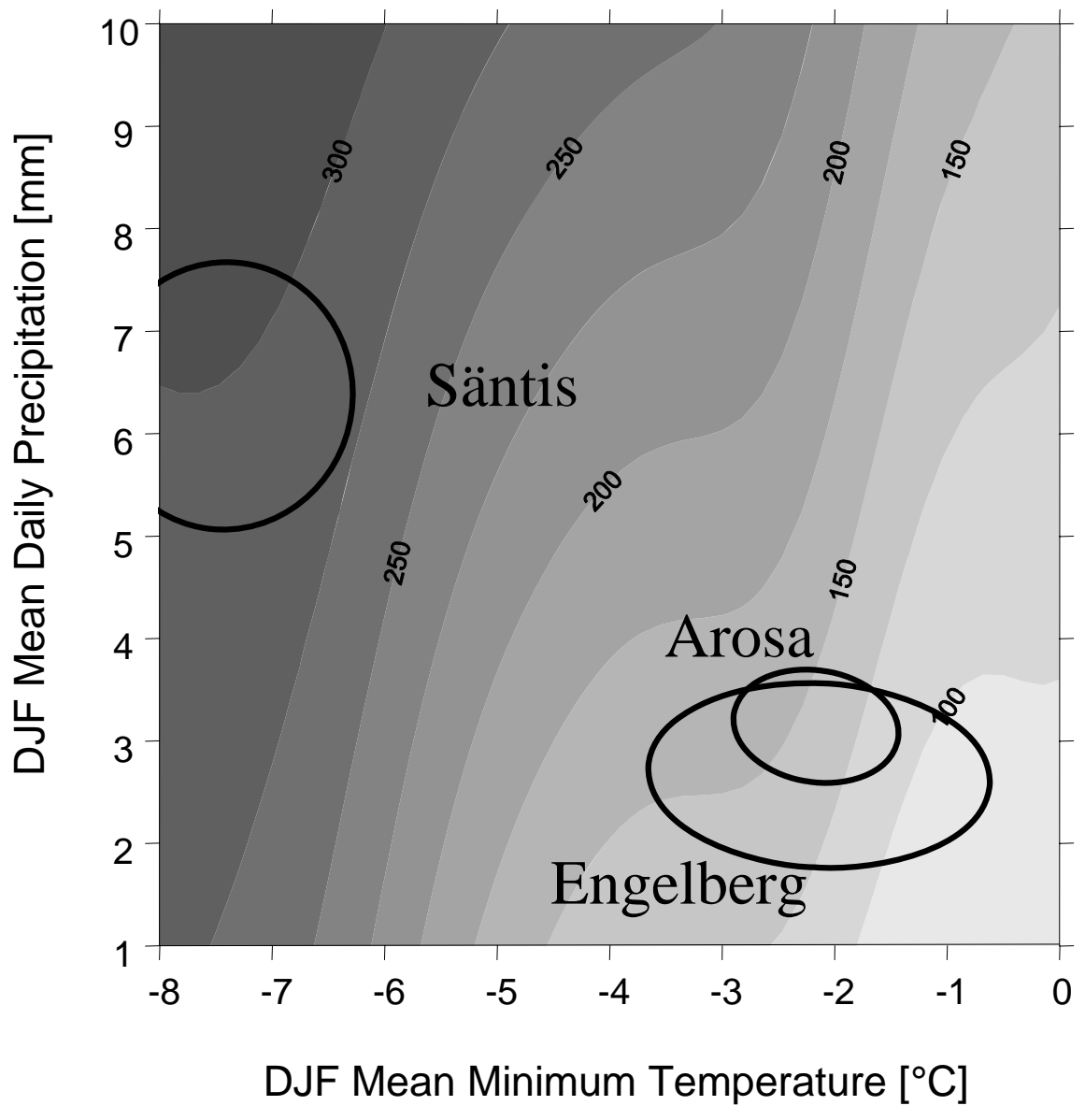

Mean Snow Depth [cm] 350 325 300 275 250 225 200 175 150 125 100 75 50 